\title{
Mining and Metallurgical Section.
}

\author{
[Stuted Meeting, October r3, 1897.]
}

Mr. Benjamin Smith Lyman, President, in the chair.

RECENT DEVELOPMENTS IN THE MANUFACTURE AND APPLICATIONS OF WIRE-GLASS.

\section{By Francis Schumann.}

Having been requested to bring before you any facts and information bearing upon recent developments in the manufacture and application of wire-glass, and being closely identified with the industry and occupied in observing its characteristics, I am enabled to present to you the following data:

Wire-glass, first suggested as early as $\mathbf{1 8 5 4}$, differs from ordinary glass only in that a sheet of wire netting is inserted in the middle of the glass sheet while in process of being rolled into plates or sheets, and while the glass is yet in a plastic state. The addition of the wire netting when successfully inserted does not affect either the strength or ductility of the glass to any appreciable extent, but does most effectively prevent disintegration or separation of the sheet after fracture, whether from impact or heat.

It is now and for several years has been manufactured to a considerable extent in the United States, England, and Belgium, and to a less extent in Germany and France. Its principal uses are for skylights, windows and partitions. It is also extensively used as a substitute for iron fire-proof shutters, because.it admits light and greatly excels in its fire-resisting qualities.

Wire-glass is made in sheets one-quarter inch thick, and of any size and shape, the maximum size of sheets being 30 inches wide by 120 inches long.

Its fire-proof qualities are extraordinary but will readily be explained if the non-conducting power of glass be considered; thus, sheets of glass set in wooden frames covered with some non-combustible material, such as asbestos cloth or ordinary tin, remained in position and prevented the passage of flames 
or hot gases, although subject to a heat on one side sufficiently great to fuse the surface of red brick. The first action of the heat was to expand and bulge the glass, and also to cause cracks. As the heat intensified, the exposed side of the glass partly fused or became plastic, but never beyond a certain degree, no doubt due to the dissipation of heat from the opposite side, which was exposed to the ambient normal air, and which prevented the temperature from reaching a point that would completely melt the glass.

The wire netting, woven of No. $22 \mathrm{~B} \mathrm{~W} \mathrm{G}$ wire, having hexagonal meshes about I inch across, is not affected by the atmospheric moisture or other corrosive agents, except to a slight degree at the edges of the glass where the ends of the wire are exposed, the imbedding of the wire within the glass proving an absolute protection.

The resistance of wire-glass to breaking does not vary from that of glass of the same thickness without the netting, because the netting lies within the neutral axis of the sheet when considered as a beam subject to a transverse load, nor is the ductility affected, provided care be taken to attain homogeneity when inserting the netting, and also in applying the proper treatment in annealing. This operation causes the greatest difficulty, in that it depends on the application of a certain temperature at a certain stage, and, because of the wellknown lack of measuring appliances or instruments, the hitting of the right conditions is largely dependent upon a personal equation. Hence it is that the breakage in one order will be practically nil, while in another it may reach an appreciable percentage, although both lots have been made by the same persons with the same methods and with the same care.

Defective annealing causes initial stresses in the sheet of glass, which, unfortunately, do not manifest themselves, no matter how carefully the glass may be examined, until after the glass is set in position and exposed to the elements, notwithstanding the strains it was subjected to when cutting to size or concussions during transportation or handling previous to being placed in position in a skylight. Acquired experience and knowledge are of course lessening these difficulties and gradually removing them. 
It has been asserted that failure of wire-glass would finally result by reason of the difference of expansion between the glass and the iron or steel composing the imbedded wire netting. That such is not the case is readily proven. The rate of expansion (or contraction) of iron or steel is about one-third greater than that of glass. This very fact makes wire-glass a possibility, and for the following reasons: The wire netting, when being inserted into the hot and plastic glass, because of its power of rapidly conducting heat, quickly attains the temperature of the glass, and, in consequence, its maximum degree of expansion, the volume of wire being inappreciable compared to that of the glass. The glass being still plastic clings to the expanded wire, but, as cooling proceeds and contraction ensues, it gradually shrinks from the glass, leaving, when entirely cooled, an annular space between it and the glass, and hence no possible strain can come upon the glass from any future variations of temperature which may arise in service.

As to the effect from variations longitudinally, it will be found that the strength of the glass in sheets one-quarter inch thick is so greatly in excess of the ultimate tensile resistance of the wire as to cause it to tear without the slightest effect upon the glass, were it possible to bring the ultimate stress upon the wire. That the wire in the glass is under tension is of course a consequence, and a most desirable result, as experience has shown, in that it tends to closely unite the glass when cracked, and thus prevents leakage from rain; this trait has often been observed and noted, and has been a reason for the retention of sheets in skylights which otherwise would have been removed.

As to the passage of light, recent tests have shown that ribbed wire-glass diffuses more light throughout a building than ordinary glass, the greater efficiency being of course due to the effect of the ribbing.

Wire-glass can be bent or curved into any form. The operation, however, is expensive, requiring special forms or moulds, and its use is consequently avoided as much as possible.

In wire-glass the architect and engineer has an article of undoubted value in the light of modern requirements. A 
medium for enclosing space, fire-proof and water-proof, transmitting light, not liable to disintegration by corrosion or combustion, and difficult of penetration, which still maintains its utility, no matter how much it is subdivided by cracks, as it will neither leak nor fall apart and injure those below when used in skylights.

I have here a sample of wire-glass, I foot square, cut from a large sheet. The piece was reheated to almost fusion (about I,200 Fahrenheit), then suddenly immersed to half its width in cold water. You will notice that the piece is yet intact and complete, suitable for any purpose for which it was originally intended.

Here, again, is another sample, showing the mode of decoration when used for partitions or screens; while this third sample is a piece of so-called "rough-ribbed wire-glass," much used for skylights and windows, the ribbing greatly adding to the diffusion of light.

Within the past year the principal manufacturers in the United States, England and Belgium have greatly enlarged their plants for its manufacture, and are making such rapid strides in perfecting the methods of manufacture that it will not be long before wire-glass will be generally accepted as an established commercial product, its process of evolution being analogous to that of steel.

In conclusion, I will exhibit several lantern slides illustrating the action of heat upon the glass, as also a view of a skylight roof, from below, of a large structure in this country, which will permit of a comparison of wire-glass with ordinary skylight-glass.

Figs. $I$ to 8 illustrate a test of the fire-resisting qualities of wire-glass, made under the supervision of Secretary Chas. A. Hexamer and Inspector Wm. McDevitt, of the Philadelphia Fire Underwriters' Association, on April the 3oth, I $896 . *$

* The brick test-house referted to in accompanying series of views, was built of 9 -inch walls, measuring $3^{\prime} \times 4^{\prime} \times 9^{\prime}$, interiorly. Iron grate-bars were placed about 2 inches above the ground level, immediately above the cross. shaped openings arranged to supply air for combustion. The top of the testhouse was roofed with a skylight, one side with $/ / 4$-inch wire-glass, and the other with $1 / 4$-inch rough-rolled skylight glass of the ordinary kind. The 
Fig. I shows the test-house immediately after lighting the fire and closing the door.

$F_{i g} .2$ is a view taken two minutes after lighting the fire. The smoke had blackened the glass of the door and cracked the glass in the window. The half of skylight glazed with $1 / 4$-inch wire-glass is on the same side as the window, and shows in this picture.

Fig. 3 is a view taken three minutes after starting fire. The heat is sufficient to warp the wire-glass. The plain glass on the other side of the skylight had just commenced to break and fall.

Fig. 4 shows the condition of things fifteen minutes after starting fire. There is evidence of considerable increase in the intensity of the heat, and evident charring of the wood in the frame and door incased in tin.

Fig. 5.-Fire twenty-five minutes under way. Wire-glass in door and window at a red heat, sufficient to cause the glass to buckle. This buckling was due largely to portions of the firewood pressing against it while in this plastic condition.

Fig. 6.-Fire thirty-five minutes under way. This view shows the side of skylights, glazed with ordinary glass, which had fallen in five minutes after the fire had started. The portions of glass still remaining were protected from direct heat by the thickness of the brick walls immediately underneath, which also prevented them from falling.

Fig. 7 is a view taken after water had been thrown on the skylight while the fire was at its greatest intensity. The walls had cracked, and the plain glass was partly melted, as is seen in the opening at the opposite side of the building. The wire-glass in the window below, owing to the absence of clips, had curved outward at the top. The door was still intact and in position.

Fig. 8 is a view taken after the fire had been extinguished and water had been thrown on the glass with a hose. All of the wire-glass was intact. The panel of the door is seen with the tin covering ripped off, showing the charred condition of the wood inside, but which still retained its form.

Fig. $\mathrm{g}$ is a photograph of the ruins of two factory buildings at Newark, N. J. One was a five-story and the other a onestory building, separated by an alley 4 feet 8 inches wide. The one-story building contained eight windows, furnished with wire-glass, set in angle-iron frames, in place of iron shutters. The view shows one of these windows after the fire, which caused the fall of the smokestacks of the large building and the destruction of all of the small building; a portion left standing containing the window.

frame of skylight and the sash-bars were of wood covered with tin, both being glazed with wire-glass held in place by iron clips. A window of $1 / 4$ inch thick wire-glass, with iron frame, was set in one side of the house, and the wooden door, with an upper panel of $1 / 4$-inch wire-glass, was tin-lined. The tin covering the woodwork has lock seams.

A quarter of a cord of wood, thoroughly saturated with oil and mixed with resin, was placed on the grate-bars ready for lighting. 
Jour. Frank. Inst., Tol. C.T. V., Fehruary, 1898 .

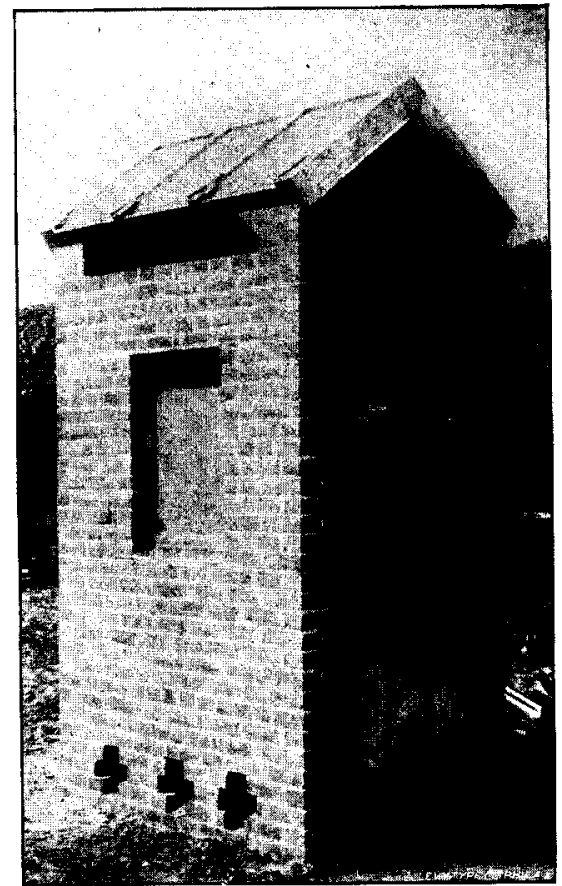

FIr. 1. - Test-house at starting fire.

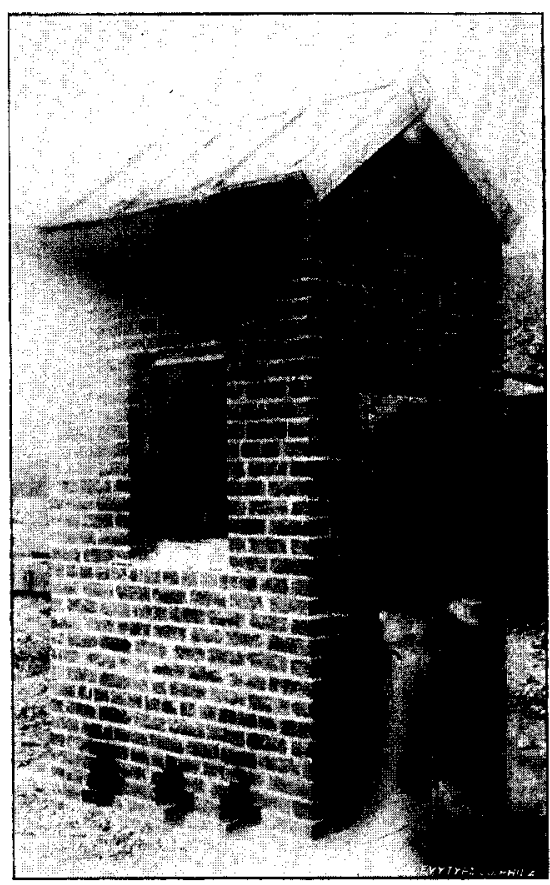

FIG. 3.-After three minutes.

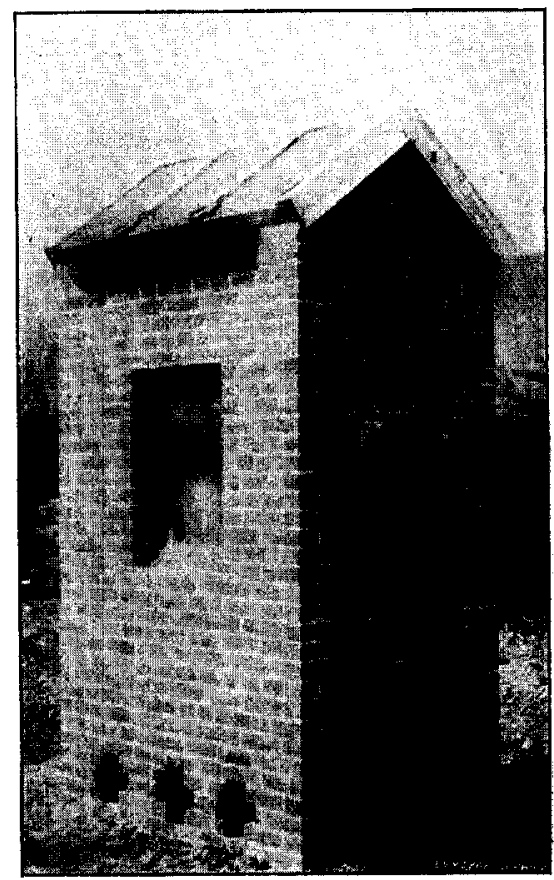

FIG. 2.-Two minutes after lighting fire.

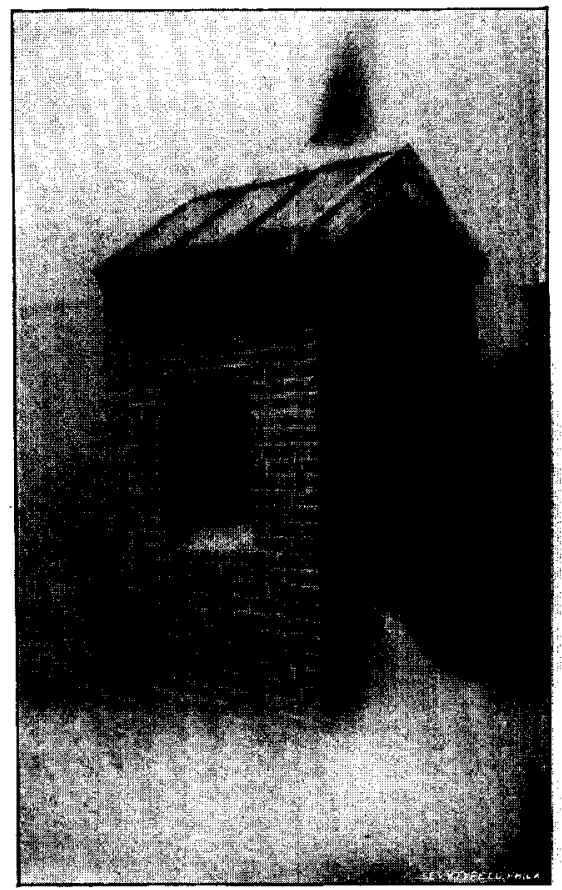

FiG. 4.-After fifteen minutes. 
(Schumann-Wireslass.)

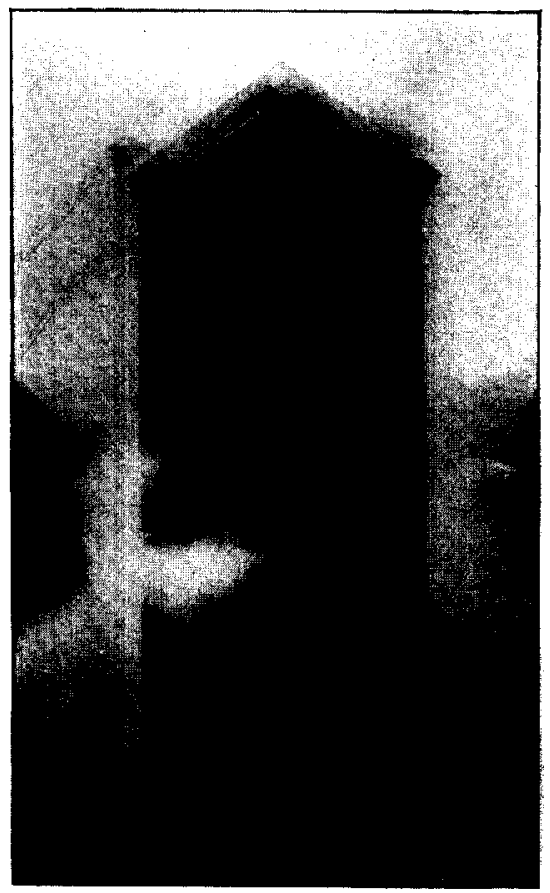

FIG. 5.-After twenty-five minutes.

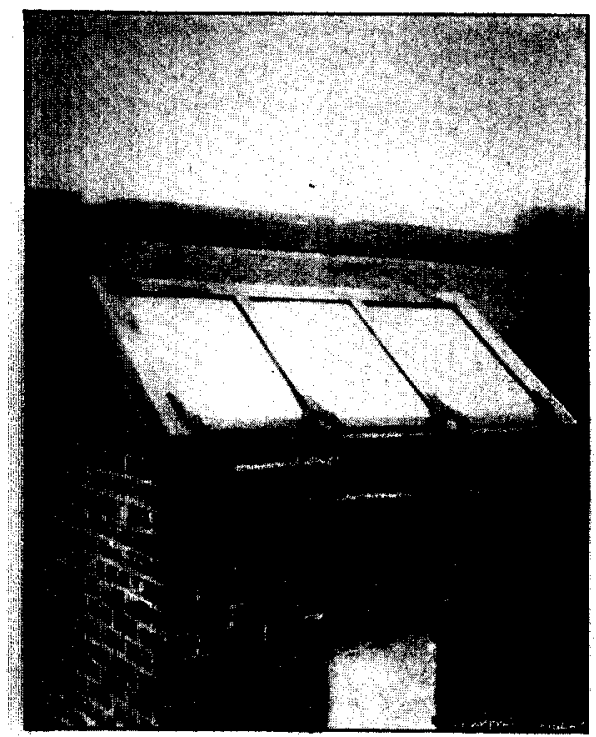

FIG. 7.-After water had been thrown on skylight. Fire at greatest intensity.

OF WIRE-GLASS.-[HEXAMER AND MCDEVITT.]
FIG. 6. -After thirty-five minutes.

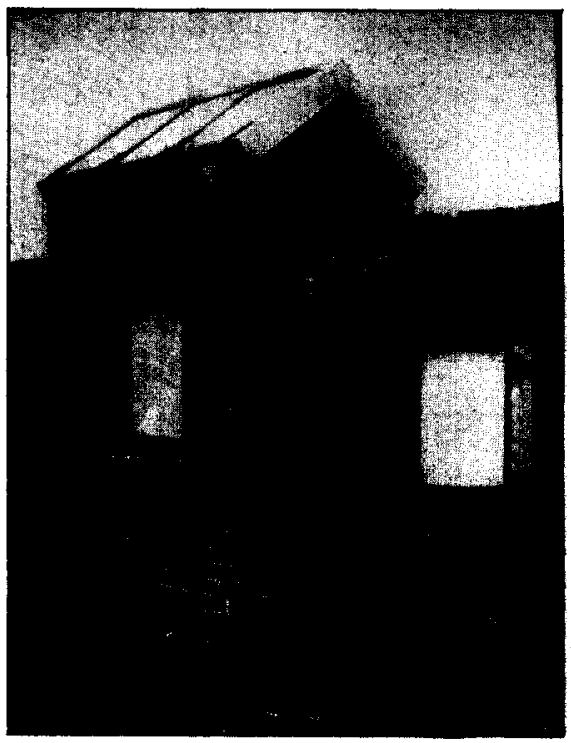

FIG. 8.-Test-house at close of experiment. 
Feb., 1898.] Manufacture and Applications of Wire-Glass. 105

Fig. IO is an interior view, looking up towards the roof, of a large train shed of a railroad station in one of the large cities of this country. The photograph was taken a few days after a severe March snow storm.

The upper part of the roof was glazed with ordinary skylight-glass, while the lower portion was wire-glass. How the

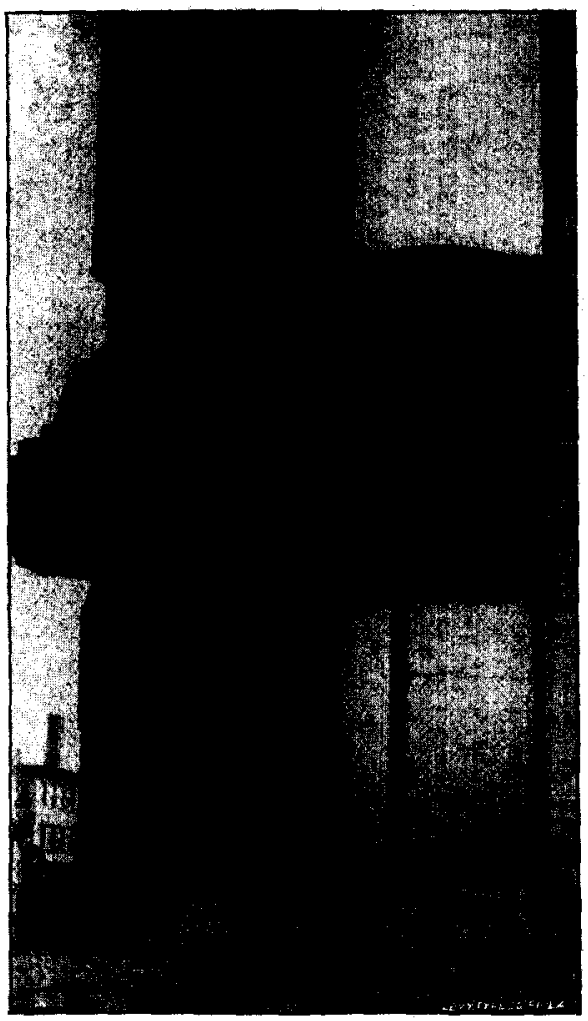

Fig. $9-$ Wire-glass window in building of Newark Stamping Company, after fire.

storm affected the ordinary glass will be noticed by the number of broken sheets. The opacity of this part of the section of the skylight is caused by the soot clinging to the glass, the safety wire netting stretched beneath interfering with the proper cleaning of the glass.

While many of the wire-glass sheets were cracked by the 
storm, none of them were displaced, and they remain in place to this day. Attention is also called to the bright appearance of the wire-glass section, which denotes its clean condition. This

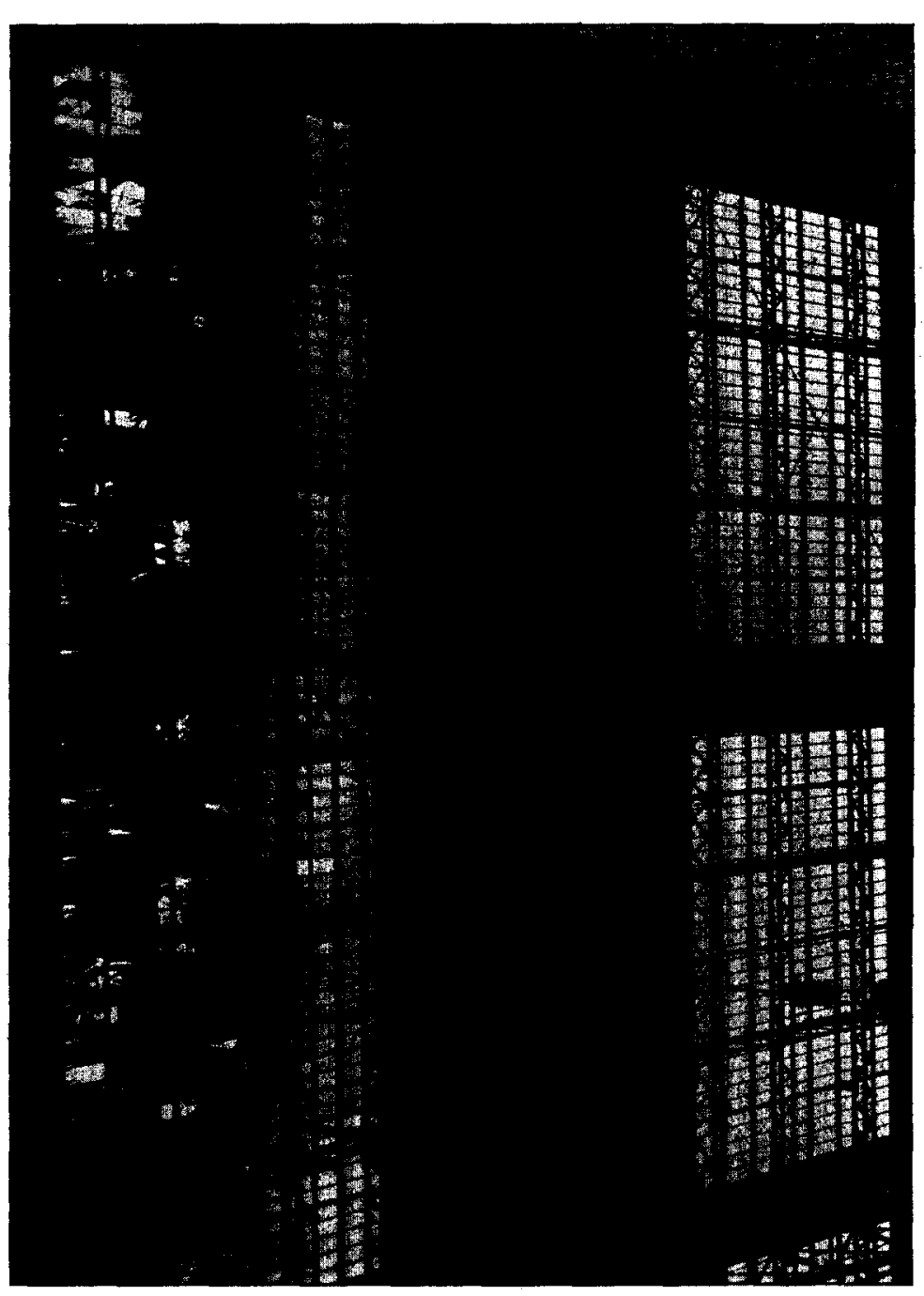

is due to the fact that it requires no. protecting shield of wire below, which is necessary with ordinary roof lights, and hence interposes no difficulty in cleaning. 